\title{
5. Policy workers tinkering with uncertainty: Dutch econometric policy advice in action
}

Annick de Vries, Willem Halffman, Rob Hoppe

To appear in H. K. Colebatch, R. Hoppe \& M. Noordegraaf (Eds.), Working for Policy (pp. Ch. 5). Amsterdam: Amsterdam University Press (accepted, expected 2010)

\section{Experts and civil servants at work, together}

Every year, on the third Tuesday of September, the Dutch cabinet presents its plans for the coming year to Parliament. There is much pomp and circumstance, which is unusual for a political culture that is otherwise proud of its modesty and restraint. The Queen is transported to the Parliament buildings in a golden carriage, cheered on by the masses and accompanied by an extensive horse guard. The animals have to be brought in from all over the country for the event, as the state itself no longer owns enough horses. The Queen's state of the nation speech then kicks off weeks of Parliamentary quarrel over the budget, minutely assessing the work of government. As MPs of the numerous parties in Dutch politics skirmish over each and every element in the budget, one feature of the budget stands above debate: the assessment of future economic growth by the nation's official econometricians is accepted as the very best estimate and the only one that really counts. In spite of obvious and acknowledged uncertainties that could boost or break the nation's wealth - such as wars, bank crises, or simply bad weather - the judgement of these experts keeps disagreement contained: all agree on the state of the economy, both now and in the near future.

This situation, pervasive in Dutch politics, is all the more remarkable as the relation between specialised experts and policy makers is generally a difficult one. Civil servants and politicians typically complain that experts do not provide 'useful' knowledge or do 
not appreciate the context in which knowledge will be put to work. Conversely, experts complain that policy makers abuse their findings or fail to understand the qualifications and uncertainties of the advice. In order to maintain cooperation, both parties need to adjust mutual expectations and negotiate their roles.

This chapter analyses how this 'boundary work', as we call it, occurs at one particular body that provides economic expert knowledge to the Dutch government, the Netherlands Bureau for Economic Policy Analysis. This government institute has a key role in Dutch public policy, in that it provides knowledge that is considered highly reliable and is invariably deployed as such in public debate. We will try to understand how experts and policy makers together manage to produce economic assessments that are widely accepted as correct for all practical purposes, in spite of considerable uncertainties involved. In spite of these uncertainties, acknowledged by both experts and policy makers alike, these actors manage to produce what are considered solid cognitive foundations for economic policy, channeling political energy to what ought to be done rather than to what is the state of affairs. The focus of this chapter is on how this cooperation is structured.

Advisory relationships are productive when experts and policy makers work together. Empirical studies of expertise for public policy have shown that expertise that is unceremoniously dropped at the doorstep of the policy maker rarely leads to any kind of policy learning (Cash, Borck, \& Patt 2006; Huberman 1987; Landry 2003; Weiss \& Bucavalas 1977). However sensitive experts may be to immediate policy needs, effective use of new information relies on actual interaction, on working together. 
Work implies meaningful and purposeful activity, directed at the creation of a collective product. Experts do not work on policy reports by blindly and thoughtlessly following recipes, but through an understanding of the problem at hand; a meaningful comprehension of the knowledge available; the context in which this knowledge is to be used; as well as what kinds of statements are justifiable, given professional standards and values. In other words, experts operate in a social world, not as computing actors in a Euclidean void (Strauss 1988; Wenger 1998).

Working together means policy makers and experts have to negotiate tensions and disjunctions between their respective social worlds. Their respective ongoing concerns and projects never quite coincide, no matter how policy-oriented the expert or how knowledge-sensitive the policy maker. Working together implies negotiation of work across boundaries between social worlds, mutual adjustment, and tinkering with new problems as they occur. Advising policy is complex, professional work, where all eventualities have not been resolved and all role conflicts have not been settled. Civil servants negotiate complex streams of thinking and powering, in which expert advice is but one parameter in a fuzzy set of undefined equations. Because this work occurs across the boundaries of policy and expert worlds, we call it boundary work. Boundary work can more formally be understood as the attempts of actors to define practices in contrast to each other through demarcation; as well as the attempts of actors to find productive cooperation across these boundaries through a division of labour that is more or less accepted by actors involved (Gieryn 1995; Halffman 2003; Hoppe 2005; Star \& Griesemer 1989). 
This chapter describes the tinkering involved in boundary work for econometric advice to government departments in the Netherlands. Through extensive participatory observation and interviews during the production of two policy reports, one of us (AdV) has observed what occurs in these practices when new issues arise that require alignment work between social worlds (De Vries 2008). We wanted to know how economic experts tinker with their tools, tailoring advice to policy needs, while carefully maintaining the standards of their trade. From the perspective of civil servants, we wanted to know how they formulate their need for econometric knowledge and integrate that knowledge into policy projects.

Our analysis focuses on what happens when the advisory work is confronted with uncertainties. Policy may wish for accurate numbers predicting annual GNP growth rates for purposes of budgeting, for example, but economies suffer from unexpected crises, experience sudden windfalls, and even surreptitiously resist precise measurement. A skirmish on a Middle Eastern border, the fall of an unstable dictator, or the unmasking of a corrupt mega-corporation, can send shudders through the world's economies, play havoc with the oil price, or send currencies into a spin. The consequences for a small and open economy such as the Dutch one can be enormous.

Both experts and civil servants involved in the advisory process are well aware of the uncertainty which underlies their predictions and they have found ways to accommodate it in their work. Uncertainties are particularly challenging to the division of labour between experts and policy makers, as this division often relies on the argument that experts provide certain knowledge, leaving policy makers to make value-based choices in the remaining areas where experts cannot provide hard knowledge. At the 
same time, although uncertainties about the economic future are obvious and undeniable, decision makers want to convey certainty, if only to legitimate choices or provide public assurance. Unpredictable fluctuations of the oil price, the mood swings of economic conjuncture, or even the fickle mind of the national consumer are issues that cannot easily be divided between the remit of the expert and the policy maker. Sociologically, uncertainty is a monster, as it challenges the social ontologies of public expertise.

In this chapter, we want to describe how civil servants and experts together deal with this monster. They have found ways to tame uncertainties in an advisory relationship that otherwise stresses the certainty of the expert knowledge. In the next section, we will describe the role of the Dutch planning bureaus to show how important certainty is for their contribution to national policy making. In the next two sections, we will analyse the production process of two reports and show how uncertainties were addressed. In the final section we draw conclusions about how uncertainty is managed in this dense interaction between experts and policy workers.

\section{Our research sites: economists and their clients}

Economists of the Netherlands Bureau for Economic Policy Analysis provide the national executive with authoritative analyses of the Dutch economy and how it is expected to develop in the future. Its staff (200 people) produces about one hundred reports every year, with the Departments of Economic Affairs and Finance as their main patrons. The Bureau operates at some distance to the Ministry, where it carefully guards its reputation as an independent institute for the analysis of policy outcomes ex ante and ex post, based on the calculative reason of econometric models. For example, the bureau will assess the expected effects of tax changes on income distribution, the economic benefits of 
infrastructure projects, or the state of the government's budget in light of European monetary agreements.

The Bureau has a remarkable role of authority in the Dutch policy world. Its regular economic growth predictions are featured prominently in the media and form crucial interventions in the periodic adjustment of national policies. Political parties submit election manifestoes to the Bureau to assess the likely effects of their political plans on the Dutch economy. Its econometric analyses also form an input to negotiations between the social partners and at several points in policy cycles for major issues such as the national budget, government is legally required to submit its plans to these experts. The Bureau has so far been able to maintain their role as neutral arbiters of economic realism, even against criticism of technocracy or against competing challengers among Dutch economists (Halffman \& Hoppe 2005).

The economists of the Bureau trace back their role definition to their founding father, the Dutch economist Jan Tinbergen, the first director of the Bureau in 1947. Tinbergen defended the role of economics in policy making by invoking the typical sacred narrative: policy makers formulate the desired policy outcomes, while economists can advise on what policy instruments can provide these outcomes. For example, in the traditional Keynesian economics of the era, economists could suggest how to achieve a desired balance between unemployment and inflation, but it was up to the politicians, not the economists, to identify the desired outcome (Don 2004).

Although the establishment of the principles for policy analysis by the planning bureau is presented as a historical discontinuity by a stroke of genius, the debate over the role of a planning bureau already started in the 1930s, when 'economic planning' was 
seen as a way to tackle the profound economic crisis after the stock market collapse of 1929. By the time the Bureau was established, centralist planning had already lost a lot of its credentials, but differences of opinion on the role of economics in policy continued to exist. When the Bureau produced its first reports, the notion of 'planning' in its name was already being frowned upon, but its Dutch name, which literally translates as 'Central Planning Bureau' was anchored in law and has remained unchanged since (Van den Bogaard 1998).

The economists at the Bureau guard their role carefully and are quick to distance themselves from any notion of 'planning', seen as technocratic and 'not of this time'. For this reason, the English name of the Bureau refers to 'Economic Policy Analysis' rather than the 'Central Planning' of the Dutch name. Senior members of the bureau will also vehemently object to terms such as 'assessment' or 'policy advice' to describe their work, as these are seen to imply normativity, telling politicians what to do, or taking sides in political disagreements. They see their role purely as one of analysis: a neutral study of the likely outcomes of policies (Hoppe 2008).

However, in the practice of policy debates and shifting governance structures, these principles require further elaboration. In 1996 a protocol for planning bureaus was published, formalising some of the principles about the kinds of tasks that experts can and cannot perform for policy makers. There have also been some recent skirmishes at the sister institute for the environment about how merely intended, but not yet accepted policy is to be assessed in the analysis of expected policy outcomes. Experts in planning bureaus are not expected to question the political acceptability of policy intentions. They may have doubts about civil servants trying to exaggerate future policy effects by 
including intended policy rather than established policy, but if the experts were to question the political acceptability of such policies, this could undermine the position of the responsible Minister in Parliament.

Conversely, there are also limitations to what civil servants are allowed to do in this respect. The expert economists insist that civil servants can ask questions or suggest alternative scenarios for the future, but that the outcome of their calculations will not be changed. In this sense, even the large econometric models of the Dutch economy that form the linchpin of their toolkit serve to organise the science/policy boundary. Civil servants can have a say on the input side of the models, or even request the construction of expansions of the model, but what happens in the models is considered the domain of the economists.

Here too, the general principle requires negotiation in concrete cases. For example, policy proposals that are to be 'analysed' by the planning bureaus may not always fit into the models, or may not even be sufficiently articulated to allow for calculation of results. In such cases, the economists tend to accommodate policy makers with suggestions on how to further articulate policy or advice on policy instruments that will produce the desired effects. Huitema has described the careful maintenance of neutrality when planning bureaus provide such advice to political parties in the analysis of election manifestoes (Huitema 2004).

Thus the role of the Dutch planning bureaus, and that of the Central Planning Bureau in particular, can be understood as a linesman of politics: by predicting the likely outcomes of policies that are being considered, the planning bureaus define what is at stake in policy making (Halffman \& Hoppe 2005: 140). The exceptional level of 
cognitive authority of the Bureau is partly a matter of convention: senior policy makers are aware that these analyses are best guesses that are not always as precise and certain as presented in the media. Nevertheless, there is broad-ranging consensus among policy practitioners that it is best to accept these assessments, in order to enable the complex negotiations that have long characterised Dutch politics, from coalition formation to negotiations with socio-economic partners. Challenges to these assessments do occur, but these are often seen as politically weak, as a way to hide weaknesses in policy proposals by attacking the expert messenger. The cognitive certainty the planning bureaus provide seems to simplify the political negotiation, that can focus on bargaining rather than bickering over what is the state of affairs (Halffman 2009).

In light of the importance of neutrality and certainty, the accommodation of uncertainty in this advisory practice is a fascinating puzzle. If the key element in the role of econometric 'policy analysis' is to provide stable ground for budgeting, coalition formation, or wage negotiations, then too much obsession with uncertainties in predicting the economic future would paralyse the endeavour. However, ignoring uncertainties would undermine the epistemological legitimacy of the advisory project, as there are obvious inaccuracies in predictions. The Bureau's economists, at the insistence of an international expert evaluation committee, have acknowledged these inaccuracies. Assessments of past predictions for one-year predictions of GNP shown an average accuracy of $\pm 1.5 \%$ in the period 1971-2002 (Kranendonk \& Verbruggen 2003). ${ }^{1}$ For purposes of government budgeting, even fluctuations of a few percentage points can affect departmental budgets by millions of Euros. So how these economists contain uncertainties, acknowledging their relevance without letting them run rampant? 
Uncertainty threatens the advisory relationship in a more profound way as well. If the experts are responsible for the creation of certainty and the policy makers for choice in light of political and value-based preferences, then uncertainties constitute an uncomfortable grey in-between zone. More explicit attention to uncertainties requires new accommodations in the division of labour between experts and policy makers. In this sense too, uncertainty is a footloose mongrel that ignores the carefully nurtured enclosures in the maze of power/knowledge. How do civil servants discipline this mongrel by boundary work?

\section{Economists and the budget cycle: the Central Economic Plan}

One of the most important reports the Bureau produces is the Central Economic Plan (CEP): a statutory annual report to government that provides a national economic prospect for the current and subsequent year. The CEP contains crucial figures about important economic variables, such as the expected inflation rate and the gross domestic product (GDP). Above all, it is crucial in the construction of the national budget because it provides the data that support budgetary negotiations within the administration. Because of its key importance in economic and financial policy, the Bureau is keenly aware that it needs to provide econometric projections that are both accurate and policy relevant. We observed and analysed the production of the CEP edition of 2005.

In order to guarantee coordination of the report with policy needs, there is intensive interaction between the Bureau experts and civil servants over its content. This interaction starts in scoping meetings during the early stages of planning the report, where the main topics are established. From the very beginning, uncertainty was on the agenda of these meetings. The CEP team and the policy staff involved co-operated to 
manage uncertainties in such a way that demand and supply of uncertainty information were in agreement.

The issues addressed involved textual matters, technical questions about the quality of data, but also more substantial concerns. Especially the making of uncertainty variants shows how uncertainty fine-tuning between the $\mathrm{CPB}$ and the ministries was realized. The CEP team asked the civil servants which uncertainties for the coming year required closer attention. Both experts and civil servants considered selective uncertainty variants to be a useful tool to analyse and communicate uncertainty.

Two particular moments in which these suggestions could be made were the technical meeting (with the financial-economic policymakers) and the contact persons meeting (with more ministries and a broader approach). The writing of the CEP is a relatively open process (Borstlap et al. 2007) and the (draft) uncertainty variants were presented to the policy workers involved in advance, giving them an opportunity to react and to ask for additional variants or for alterations in the variant subjects.

In the technical meeting, a discussion arose about the adequacy of econometric projections due to large fluctuations of the oil price. The draft version assumed a decrease in the oil price, which was highly questioned by those attending this meeting. After sending out this draft version, the oil price had already risen considerably. Furthermore, civil servants argued that the negative and the positive risks or uncertainties had to be in balance, to avoid a too optimistic view of the economy. This reflected the concerns for budget austerity of the civil servants from the Ministry of Finance involved in the meetings. Since the ministries' representatives thought the CEP created a carefree atmosphere while the risks were enormous, their suggestion was to nuance this positive 
tone by paying more attention to 'downward risks' and in particular to the oil price. This led to the following request with regard to uncertainty information:

CPB1: 'The certainty concerning the oil price in 2006 is lower than in 2005.' FIN: 'Are you willing to make uncertainty variants on that?'

CPB2: 'Yes. We don't know yet the precise interpretation, but we will work on that.'

Similarly, in a meeting with civil servants of other ministries a few weeks later, the desire for an additional uncertainty variant was also expressed. Amongst others, the representative of the Ministry of Economic Affairs explicitly suggested to bring the uncertainty regarding the oil price prominently to the fore. The majority of representatives from the ministries agreed that the uncertainty around the oil price was too important not to make a variant. The CEP team leader replied that they were fully aware of the uncertainties and risks, and that they were ' $[. .$.$] busy making an additional$ uncertainty variant about the oil price.' Although originally raised as an issue related to budget concerns by civil servants of the Ministry of Finance, the oil price variant became a project that carried support from other civil servants and the Bureau's economists as well, as there was wide agreement that the oil price was an important issue for the projections.

This mutual consultation is not built from scratch for every report. In fact, the production of the CEP and similar periodic reports has become a well-structured process, with a well-rehearsed protocol which although unspoken, is generally known by the civil 
servants and experts involved. Because of this standard mode of working, the policy workers knew their role and could anticipate the CPB gatherings. The protocol routinises the planning of meetings and the production process of a report, creating clarity about what both parties in this cooperation can expect.

Similarly, both civil servants and experts share an understanding of what variants are and how they can be used to address uncertainties. Since making uncertainty variants was a routine way to deal with uncertainties in short term reports and because of the close contacts with particularly the Ministry of Economic Affairs and the Ministry of Finance, the policy workers involved knew beforehand that they would have the possibility to suggest topics for the uncertainty variants. They prepared uncertainty variant suggestions by consulting specialized colleagues in order to get a picture of important developments that could affect the economic situation. The representatives from the ministries internally gathered variant suggestions. At both the Ministry of Finance and Economic Affairs, there seemed to be a one-to-one alignment between the topics of the CEP and the specializations of the policymakers. The ministries had a specialist for each 'standard' CEP topic, which could foster the preparation of suitable uncertainty variants. Because of this knowledge, it was possible to thoughtfully prepare those suggestions prior to the gatherings at the CPB. Policy workers could anticipate how the bureau would address and even present uncertainty in the CEP and hence formulate their questions and concerns in ways that the experts could handle.

This shared knowledge has come about through well-honed cooperation and personal networks. Historically, civil servants and the Bureau experts have had close contacts. Personnel exchanges are also common and it is not unusual for social networks 
to link back to a handful of university departments that train these economists and financial experts. These close contacts create a shared discourse and understanding of the world, which enable interaction during the writing process of the CEP, allowing for the systematic transformation of wild uncertainty into uncertainties useful for policy.

\section{An ageing population: a non-routine report for policy}

Apart from standard reports, the Bureau also produces a large number of non-routine reports, ranging from brief ad hoc papers answering specific policy questions, to extensive dossiers on major policy issues. One such issue confronting public finances that has been high on the policy agenda in recent years is the aging of the Dutch population. The report Ageing and the Sustainability of Dutch Public Finances (further called AS) is a long horizon CPB study that looks ahead to 2040. Due to population ageing, the number of pensioners will increase which will lead to increasing financial burdens. Rising financial burdens result in a gap between government expenditures and revenues ('sustainability gap'), which requires budgetary adjustments. The study assesses the sustainability of public finances as a consequence of ageing and explores several policy options to restore fiscal sustainability.

As in the CEP case, frequent interactions with policy workers were facilitated by the use of a shared understanding of how uncertainty can be addressed. However, the task at hand was much more complex. The issue required a projection reaching several decades ahead, rather than just to next year. In addition, no standard protocol was available, the range of ministries and expertise was larger, and some aspects required the development of a new computer model. This complexity put the cooperation under more 
stress, but at the same time revealed to us more precisely how civil servants and the experts are able to manage uncertainties productively.

We found that an important heuristic underlying successful uncertainty management is the use of a shared classification scheme for uncertainties and uncertainty tools. This involves a general division of types of uncertainty that helps civil servants to thematise uncertainties. This translates into a clear set of instruments the experts use, reducing uncertainties to a manageable set, while at the same time resolving potential conflicts over the science/policy boundary. Thus the classification scheme facilitates cooperation by aligning the uncertainties of interest to civil servants with the cognitive resources and capacities of the experts, while organising the division of labour between them.

The main principle of classification is a distinction between sources that can affect projections. Policy intentions are a source of change that can alter econometric projections, but that have to be treated as given. For purposes of policy analysis, alternative measures can be 'calculated through'. A second source consists of changes in the world that are considered unpredictable, such as changes in life styles or wars. These are dealt with through variants, as we saw in the CEP case. A last one is seen to originate in the imperfection of knowledge and data, raising concerns about sensitivity of the policy analysis. Even though this classification is shared and seems relatively straightforward, the practice of writing reports still requires adjustment and tinkering to fit the monster into these boxes. The struggle of the AS team with uncertainty over future interest rates shows that there is a limit to such adjustments. Deviations from the basic classification scheme create confusion and undermine the cooperation. 
When the writing process of the AS report started, the most likely value of the interest rate was 3\%. However, the Bureau experts faced important issues, like the justification of the level and future development of the interest rate. Discussion arose about the uncertainties involved, the sensitivity of the outcomes, and about how these issues should be resolved.

One serious option was the creation of an extra baseline projection of $3,5 \%$, in addition to the $3 \%$ one. The reason to choose for $3,5 \%$ was because the team wanted to remain in line with the interest rate the European Commission used: judgments of other policy experts were taken as frame of reference (e.g. Tetlock 2005). The team thought this was a good solution, since they expected the policy workers to only look at the baseline projections and not at the sensitivity analyses. They argued that the two baseline projections were more important to illustrate uncertainties than sensitivity analyses. The main drawback they saw was that policy workers would only focus on one baseline projection as is reflected in the following discussion:

CPB 1: 'Then, you show that [the baseline] is uncertain.'

CPB 2: 'But policymakers will then just take the average, which is then $3,25 \%$, which would make the presentation of two baseline projections useless.' CPB 3: 'But 3,25\% actually is a very good figure.'

Another team member asked, with regard to the two figures $3 \%$ and $3,5 \%$ :

CPB 4: 'Does this bandwidth represent reality or is it politically desirable?' 
CPB 5: 'If you would take $2,75 \%$ to $3,75 \%$ you don't have any connection with Brussels anymore. If you take the cautious 3\% to 3,5\%, then you make it easy for politics. Otherwise, the study group would face more pressure. So, just take $3 \%$ to $3,5 \%$.'

By the end of the meeting, the Bureau's experts agreed. Rather than present one discount rate and an additional variant, the team chose two baseline projections with different discount rates. It is noticeable that the AS team took into account the interest rate calculations of the Economic Policy Committee in Brussels, despite the fact that both authorities used different ways to calculate the interest rate. A senior official of the Ministry of Finance was able to convey (without actually saying it) that this was a good decision as the interest rate figures of both authorities remained comparable in this way: according to both calculation modes, the interest rate was $3 \%$.

Thus the AS team tried to tame the uncertainty of the interest rate in a baseline, effectively creating two different scenarios for the future. Concerns about perception of this approach by policy was part and parcel of the decisions made: this was not only a matter of creating a realistic projection, but also of preventing an easy way out for policy makers through what were seen as overly optimistic scenarios. Effectively, the experts were trying to discipline the civil servants into what they saw as good policy making. The relationship with the civil servants may be productive and geared to the communication of useful uncertainty, but this does not exclude attempts at mutual disciplining.

Nevertheless, usefulness remained a dominant concern. One specific audience for this report was an interdepartmental study group of civil servants, consisting of 
specialists on issues related to aging. The AS team was aware that its report would serve as input to the study group and was constantly aware that their analysis had to be useful to these civil servants. A larger range between the two baseline projections was considered more problematic for the study group to deal with, as it would make create a much wider range of future expectations. This implies that the AS team intentionally provided the study group with (supposedly) 'manageable' information and clear figures, narrowing down options and uncertainties.

These pragmatic interventions in the packaging of uncertainty also had to be justified to peers. Beside the discussion within the project team, the authors also consulted other $\mathrm{CPB}$ experts on the problem of the interest rate. One expert criticized the (relatively) small range between the two interest rate values and said that the two baseline projections should deviate more. Another expert argued that the smaller the difference between the figures, the higher is the probability that 'you have to take account for it in Autumn', implying that in that case the chance to make incorrect calculations is larger and that it might be necessary to do recalculations later in the year. A presentation of a baseline with little attention to uncertainty increases the probability that one has to recalculate it periodically, for example by making an update report. This is already the case for periodic CPB reports such as the CEP, but for long horizon studies such as AS, the updates would be more complex and time-consuming.

A team member, who was also on the CPB's management board, and a CPB expert (who did not belong to the AS team) discussed the uncertainty range and whether the message would be properly understood by the focal users. In this situation, the CPB analysts considered how much room to leave for politicians: the interpretation space for 
politicians becomes larger by providing extensive uncertainty information rather than by providing one baseline projection.

1: 'OK, we have to take 3\% in any case, because of Brussels, and then, well, let's take one percent-point higher. But then the average is not 3,25\% [CPB's best guess - adv]. If you take $3 \%$ and $4 \%$, then the politicians will take $3,5 \%$ and that's not the most plausible value.'

2: 'You wouldn't want to reduce the uncertainty regarding the interest rate to that extent just in favour of the output, would you? You should focus on the uncertainty in the input, not on the uncertainty in the output!'

Another team member agreed with taking the smaller bandwidth (of 3\% and 3,5\%) as 'in case of a large bandwidth, you leave the choice to the politicians.'

The issue continued to haunt the team. Not only was there the problem of how to keep the politicians on their toes, of producing useful knowledge, or staying in line with peers, as well as Brussels projections, very practical concerns of how to present information clearly also played a role. Eventually, during a later meeting, the team decided to take $3 \%$ and $4 \%$ as interest rate values for the two baseline projections:

1: 'In order to get rid of the discussions about the current rate, we'll take 3 and $4 \%$.'

2: 'Wouldn't it be easier for the sake of communication to take only the value 3?' 
3: 'For the graphical figure, it doesn't make difference whether you take one or two values.'

1: 'And, with [only ] the value 3, we are making ourselves vulnerable; we have to be able to explain [the large fluctuations in the interest rate ].' [...] 'And actually, I don't want to get too much technical discussions about the interest rate.'

A few weeks later, the AS team had to present its proposal for two baseline projections to get the opinion of the ministries' representatives. Finally, these opinions were to be decisive in this discussion. The main questions were how the civil servants had to interpret two baseline projections and the status of the baseline projections in relation to variants that were proposed. For example, a representative of the Ministry of Economic Affairs asked, because of the political importance of the subject, whether those projections and the variants could be considered equivalent. The team leader replied explicitly that the projections had a higher status than the variants. The 'basic' baseline projection (based on the 'original' discount rate of 3\%) was slightly more important than the 'alternative' baseline projection (based on a discount rate of 4\%). Also another team member underlined unambiguously that the two projections were not equivalent to each other. This means that, despite the acknowledgement of large uncertainties, the team obviously prioritised the outcomes of the 'basic' baseline projection; the 'alternative' projection was 'only' calculated to illustrate uncertainty.

By entering alternative baseline projections, the team had transgressed the shared classification of uncertainties. Policy workers did not understand the status of this new category and were clearly also concerned about how they would perform in their own 
work. Eventually, directors from both sides (i.e. the department directors of the ministries of Finance, Economic Affairs and Social Affairs and Employment, and the director of the $\mathrm{CPB}$ ) met to discuss the interest rate and its presentation form. The representatives of Economic Affairs advocated the presentation of two interest rate projections, but the other ministries had different opinions. For example, a senior of the Ministry of Finance explained that the Finance representatives were not in favour of the presentation of two projections. They felt that having two projections would not be effective since the base projection (or CPB's 'best guess') would not be clear when presented in this way. An official of the Ministry of Economic Affairs explained that the AS team then tried to find a balance between the different opinions of policymakers and their own views. In the final AS report, only one baseline is presented and, after serious consideration, the AS team stuck to the 'initial' classification scheme (consisting of the tripartite distinction between baseline projection, sensitivity analyses, and policy analyses).

\section{The profane work of taming uncertainty}

Producing uncertainty information in policy analyses that is actually useful for policy workers and politically accountable decision makers is not a precisely defined, deductive system. In spite of attempts to formulate uncertainty analysis by experts and uncertainty assessment and management by policy workers in the more sacred fact/value language of protocols, guidelines, detailed taxonomies, or analytic structures, taming uncertainty uneasily straddles the fact/value divide. Hence, it requires careful negotiation, not only of the treacherous terrain of (future) economic processes, but also of the boundary work with policy, and the practical concern of writing readable reports that are finished by the deadline. 
We have shown how this complexity is managed through frequent interaction between policy workers and experts; a well-designed writing process that helps to establish mutual expectations; a shared world of personal contacts and knowledge; and, crucially, a shared framework for organising uncertainties. The latter could be found here in the form of a relatively robust, shared classification of uncertainties. In the boundary work between economic experts and policy makers, we see these elements as crucial heuristics that enhance alignment between the planning agency and the ministries. The following scheme presents how this works.

Figure 1. Taming uncertainty through boundary work between experts and policy makers

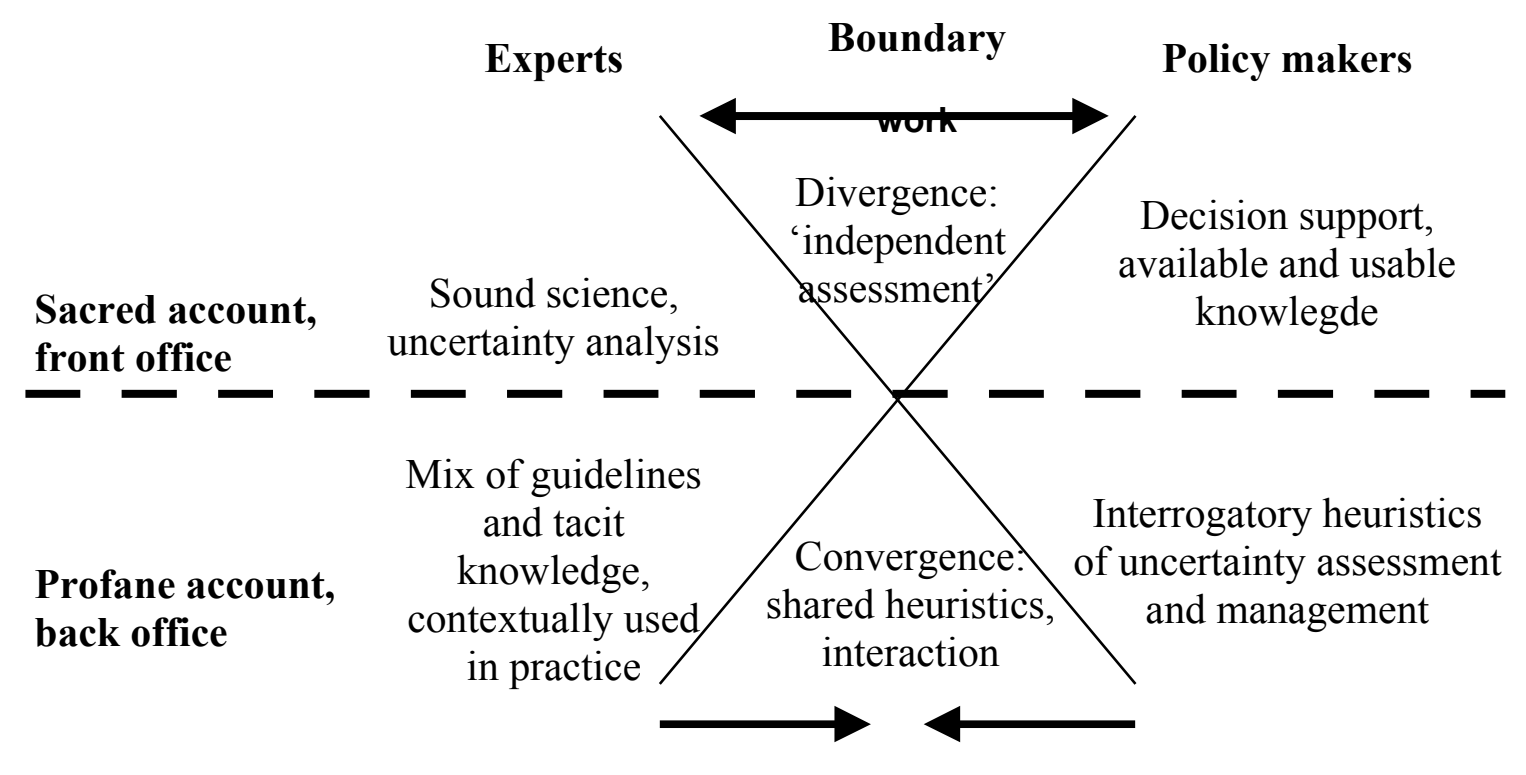

In research into discourses of boundary work among Dutch experts and policy workers Hoppe (2008) replicated findings by Bal et al. (Bal, Bijker \& Hendriks 2002) that both experts and policy workers use two kinds of accounts of their daily activities. They activate a sacred, front-office account when 'outsiders' - such as parliamentarians, or 
journalists - call upon them to explain what, how, and why they are doing things as they do. Among 'insiders' like themselves, and also in the boundary work between experts and policy workers, they use more profane, back-office talk.

In the public eye, experts of the Netherlands Bureau of Economic Policy Analysis will stress their autonomy in doing sound science. For example, they clearly reject the idea that their clients co-define the relevance of knowledge; similarly, they claim uncertainty analysis as their monopoly, uninfluenced by client or stakeholder views. Yet, in the sheltered environments of their communities of practice, they acknowledge that in the long-standing pragmatic relations with clients, and guided by the rules of the advisory game that emerged over a long period of time from practical experience, they serve politics, and are willing to qualify 'sound science' using terms like 'available and usable' knowledge.

Similarly, policy workers of departments of Finance and Economic Affairs publicly portray themselves as the sole advisors who provide decision support to their political superiors: 'We span the boundary between analysts and politicians' (Hoppe 2008). They do not deny that science plays an important role in uncertainty reduction. However, while formally tasked with responsibility for uncertainty assessment and management, they claim that, if necessary, 'we keep our expert centre on course' (Hoppe 2008). Yet again, informally they describe their practices as using interrogatory heuristics of expert reports, and translating expert views in politically acceptable and administratively feasible policy proposals.

As shown in the previous accounts of dealing with uncertainties in the short and long run, in both standard reports on the future of the Dutch economy and a non-routine 
study of ageing problem, both experts and policy workers appear to practice boundary work on the basis of their respective profane self-understandings. This appears to be a necessary condition for productive boundary work at the science-policy interface. The well known, oft repeated list of complaints about science-policy misunderstandings in the two-communities metaphor of knowledge utilization (see Williams' ch.11) accurately describes what happens when scientists and policy workers steadfastly cling to their sacred narratives; and cannot begin to admit that behind the incompatible front-office images there are more easy to align back-office practices

What this alignment allows is a working relation that provides policy workers with information that can be used as relatively stable basis for decision making and negotiation, while still exploring a limited set of uncertainties. We have tried to describe this process without passing judgement. However, as is usually the case in pragmatic approaches, there is a certain grey area where pragmatism turns into transgression. In all honesty, we should signal that this advisory practice has been criticised, for example for overly restricting political choice through a particular take on economics (Van den Berg, Both, \& Basset 1993) or for a tendency to discipline politicians (Pesch, Hisschemöller, \& Huitema 2006). Inversely, criticising these practices from the perspective of sacred accounts (Granger Morgan \& Henrion1992) or utopian rationalities (Ezrahi 1980; 1990) runs the risk of sacrificing effective contributions of knowledge to policy making - what Jasanoff has called 'serviceable truths' (Jasanoff 1990). By documenting pragmatic approaches to the taming of uncertainty, we hope to encourage debate over the development of practical and communicable but not overly restrictive forms to frame uncertainty. 


\section{References}

Bal, R., Bijker, W., \& Hendriks, R. (2002). Paradox van Wetenschappelijk Gezag: over de maatschappelijke invloed van adviezen van de Gezondheidsraad. The Hague: Gezondheidsraad.

Borstlap, H., Cann, G. J. M. T., van, Kam, C. A., de, Leeftink, B., Tammerons Bakker, J., \& Terpstra, D. (2007). Focus op Beleid: Rapport van de Commissie Beleidsgeorienteerde Toetsing van het Centraal Planbureau. Den Haag.

Cash, D. W., Borck, J. C., \& Patt, A. G. (2006). Countering the Loading-Dock Approach to Linking Science and Decision Making: Comparative Analysis of El Niño/Southern Oscillation (ENSO) Forecasting Systems. Science, Technology, and Human Values, 31(4), 465-494.

Van den Berg, H., Both, G., \& Basset, P. (Eds.). (1993). Het Centraal Planbureau in Politieke Zaken. Amsterdam: Wetenschappelijke Bureau Groen Links.

Van den Bogaard, A. (1998). Configuring the economy: the emergence of a modelling practice in the Netherlands, 1920-1955. Unpublished Doctoral dissertation, University of Amsterdam, Amsterdam.

Don, H. (2004). How econometric models help policy makers: Theory and Practice (No. CPB discussion paper no. 27). The Hague: CPB Netherlands Bureau for Economic Policy Analysis.

Ezrahi, Y. (1980). Utopian and pragmatic rationalism: the political context of expert advice. Minerva, 18, 111-141.

Ezrahi, Y. (1990). The descent of icarus. Cambridge MA: Harvard University Press. 
Gieryn, T. (1995). Boundaries of Science. In S. Jasanoff, G. E. Markle, L. C. Petersen \& T. J. Pinch (Eds.), Handbook of Science and Technology Studies (pp. 293-443). Thousand Oaks: Sage.

Halffman, W. (2003). Boundaries of Regulatory Science: Eco/toxicology and aquatic hazards of chemicals in the US, England, and the Netherlands, 1970-1995. Unpublished doctoral thesis, University of Amsterdam, Amsterdam.

Halffman, W. (2009, forthcoming). Measuring the Stakes: The Dutch Planning Bureaus. In P. Weingart \& J. Lentsch (Eds.), Scientific Advice to Policy Making: International Comparison. Opladen: Barbara Budrich.

Halffman, W., \& Hoppe, R. (2005). Science/policy boundaries: a changing division of labour in Dutch expert policy advice. In S. Maasen \& P. Weingart (Eds.), Democratization of expertise? Exploring novel forms of scientific advice in political decision-making (pp. 135-152). Dordrecht: Kluwer.

Hoppe, R. (2005). Rethinking the science-policy nexus: from knowledge utilization and science technology studies to types of boundary arrangements. Poièsis and Praxis: International Journal of Technology Assessment and Ethics in Science, 3(3), 199-215.

Hoppe, R. (2008). Scientific advice and public policy: expert advisers' and policymakers' discourses on boundary work. Poièsis and Praxis: International Journal of Technology Assessment and Ethics in Science, DOI 10.1007/s10202-008-0053-3. Huberman, M. (1987). Steps Toward an Integrated Model of Research Utilization. Knowledge, 8(4), 586-611. 
Huitema, D. (2004, 25-28 August). Calculating the political. Election Manifestoes as the meeting point for experts and politicians in the Netherlands: the case of RIVM. Paper presented at the Public proofs: science, technology, and democracy., Paris. Jasanoff, S. (1990). The Fifth Branch: Science Advisers as Policy Makers. Cambridge, Mass.: Harvard University Press.

Kranendonk, H. C., \& Verbruggen, J. P. (1999). The accuracy of CPB forecasts. The Hague: Netherlands Bureau for Economic Policy Analysis.

Kranendonk, H. C., \& Verbruggen, J. P. (2003). Trefzekerheid van CPB-prognoses voor de jaren 1971-2002 (memorandum No. 82). Den Haag: Centraal Planbureau.

Landry, R. (2003). The extent and determinants of the utilization of university research in government agencies. Public Administration Review, 63(2), 192.203.

Pesch, U., Hisschemöller, M., \& Huitema, D. (2006). The Netherlands Environmental Assessment Agency: A Servant Disciplining Politics. Paper presented at the Annual conference of the Netherlands Institute of Government, Amsterdam.

Star, S. L., \& Griesemer, J. (1989). Institutional Ecology, 'Translations', and Boundary Objects: Amateurs and Professionals in Berkeley's Museum of Vertebrate Zoology, 1907-1939. Social Studies of Science, 19, 387-420.

Strauss, A. (1988). The Articulation of Project Work: an Organizational Process. The Sociological Quarterly, 29(2), 163-178.

Tetlock, P. E. (2005). Expert Political Judgment. How good is it? How can we know? New Jersey: Princeton University Press.

De Vries, A. (2008). Towards do-ability: Dealing with uncertainty in the science-policy interface. Unpublished Dissertation, Twente University, Enschede. 
Weiss, C. H., \& Bucavalas, M. J. (1977). The Challenge of Social Research to Decision Making. In C. H. Weiss (Ed.), Using Social research in Public Policy Making (pp. 231-233). Lexington: Heath.

Wenger, E. (1998). Communities of Practice: learning, meaning, and identity. Cambridge: Cambridge University Press. 
